\title{
The Current State of Elective off-Pump Coronary Bypass Surgery
}

\section{Ahmet Baris Durukan* \\ Memorial Ankara Hospital, Department of Cardiovascular Surgery, Cankaya, Ankara, Turkey}

In recent years of coronary bypass surgery, despite the accelerated development of surgical techniques and equipment, the debate over off-pump and on-pump surgery has not lost its popularity. Classically the off-pump procedures are suitable for the patients with high rates of morbidity and potential mortality including low ejection fraction, stroke, chronic obstructive pulmonary disease and renal failure. However, the recommended surgical patient should preferentially have single vessel disease with anterior location without calcification, should be hemodynamically stable and should have every risk factor as low as possible [1]. Even this controversy creates a conflict in every single cardiac surgery resident beginning early in their education period. So, how can we decide on off-pump or on-pump "?".

The debate has accelerated following ROOBY Trial (2203 patients were enrolled) published in 2009 [2]. The trial concluded that by the end of first year, the rates of patency were lower in the off-pump group with higher incidences of composite primary outcomes including death, reoperation, new mechanical support, cardiac arrest, coma, stroke and renal failure. The study caused confliction in every single cardiac surgeon who ever preferred off-pump or on-pump. A meta-analysis published in 2012 also revealed that off-pump surgery increased overall mortality [3]. While the results of this meta-analysis were being digested by cardiac surgeons, not so soon after, in 2013, the results of CORONARY Trial were published [4]. The study comprised a higher number of patients (n: 4752) with increased risk compared to ROOBY Trial, but the surgeons were more experienced in off-pump surgery. The results were astonishing, because at 30 days and at one year the rates of composite outcomes including death, nonfatal stroke, nonfatal myocardial infarction and new renal failure were not significantly different between the groups.
This was followed by The GOPCABE Trial also published in 2013 [5]. The study included elderly patients (over 75 years of age, n: 2539). The composite outcomes were similar at 30 days.

It is very hard for a cardiac surgeon to decide whether to use offpump or on-pump. However, the degree of expertise and the overall percentage of each technique involved during the education of the resident determine the decision of the surgeon. It is quite a burden even while the guidelines on revascularization do not suggest one over another [6]. It is therefore an individual decision for now. We hope further studies will lower this burden over our shoulders.

\section{References}

1. Cardiac Surgery in the Adult, Fourth Edition. McGraw Hill Professional. Editor: Lawrence Cohn, Chapter 22, Myocardial Revascularization without Cardiopulmonary Bypass.

2. Shroyer AL, Grover FL, Hattler B, Collins JF, McDonald GO, et al. (2009) Onpump versus off-pump coronary-artery bypass surgery. N Engl J Med 361: 1827-1837.

3. Møller CH, Penninga L, Wetterslev J, Steinbrüchel DA, Gluud C (2012) Offpump versus on-pump coronary artery bypass grafting for ischaemic heart disease. Cochrane Database Syst Rev 3: CD007224.

4. Lamy A, Devereaux PJ, Prabhakaran D, Taggart DP, Hu S. et al, (2013) Effects of off-pump and on-pump coronary-artery bypass grafting at 1 year. $\mathrm{N}$ Engl J Med 368:1179.

5. Diegeler A, Börgermann J, Kappert U, Breuer M, Böning A, et al. Off-pump versus on-pump coronary-artery bypass grafting in elderly patients. $\mathrm{N}$ Engl $\mathrm{J}$ Med 368:1189.

6. Hillis LD, Smith PK, Anderson JL, Bittl JA, Bridges CR, et al. (2011) ACCF/AHA Guideline for Coronary Artery Bypass Graft Surgery: a report of the American College of Cardiology Foundation/American Heart Association Task Force on Practice Guidelines. Circulation 124: e652-735. *Corresponding author: Ahmet Baris Durukan, Memorial Ankara Hospital,
Department of Cardiovascular Surgery, Cankaya, Ankara, Turkey, Tel: +905322273814; Fax: +903123546620; E-mail: barisdurukan@yahoo.com

Received February 24, 2014; Accepted March 28, 2014; Published April 06, 2014

Citation: Durukan AB (2014) The Current State of Elective off-Pump Coronary Bypass Surgery. Surgery Curr Res 4: 186. doi:10.4172/2161-1076.1000186

Copyright: (C) 2014 Durukan AB. This is an open-access article distributed under the terms of the Creative Commons Attribution License, which permits unrestricted use, distribution, and reproduction in any medium, provided the original author and source are credited. 